\title{
Modelling future water environments of Tasmania, Australia
}

\author{
Manuel Nunez ${ }^{1, *}$, John L. McGregor ${ }^{2}$ \\ ${ }^{1}$ School of Geography and Environmental Studies, University of Tasmania, Private Bag 78, Hobart, Tasmania 7001, Australia \\ ${ }^{2}$ Commonwelth Scientific and Industrial Research Organization, CSIRO Marine and Atmospheric Research, \\ PB1, Aspendale, Victoria 3195, Australia
}

\begin{abstract}
The CSIRO Conformal-Cubic Atmospheric Model (CCAM) was used to estimate likely changes in Tasmanian precipitation and potential evapotranspiration resulting from an enhanced greenhouse scenario. The model run encompassed two $30 \mathrm{yr}$ periods: 1975-2005, designated as 'present' and 2035-2065, designated as 'future'. In the present study, model precipitation and potential evapotranspiration were tuned by comparison with measurements from weather stations. Seasonal precipitation and potential evapotranspiration climatology were then created for each time period. Results show a small decrease in summer, autumn and spring precipitation along the eastern half of Tasmania, but a substantial increase in potential evapotranspiration during the same seasons. This results in a lowering of the net water storage in water bodies, and increased needs for irrigation.
\end{abstract}

KEY WORDS: Climate change - Global climate models - CSIRO Conformal-Cubic Atmospheric Model $\cdot$ CCAM $\cdot$ Future precipitation

\section{INTRODUCTION}

This paper examines a water budget scenario for Tasmania (an island state of Australia) resulting from projected changes in climate. The climate of Tasmania, located in the Southern ocean, is influenced by westerly wind systems throughout the year. Frontal systems and cut-off lows embedded in these westerlies, along with east coast and heat lows originating in the continent are the dominant systems bringing precipitation to the island (Gentilli 1972). A precipitation map for Tasmania (Fig. 1) reflects the importance of westerly systems in bringing heavy precipitation to the mountainous western highlands, while the more sporadic east coast lows and cut-off lows affect the drier midlands and eastern regions. At frequent intervals, anticyclonic conditions dominate the island bringing dry, stable conditions. It is particularly important for Tasmania, which is heavily reliant on primary industries, to examine impacts resulting from projections of future warming.

According to the IPCC (2001), significant regional climate change will occur concurrent with global increases in temperature. Li et al. (2005) relate recent drying trends in southwest Western Australia to a strengthening of surface pressures, while other studies for the same area use coupled climate models with enhanced greenhouse conditions to document a strengthening of surface pressures and a drop in the frequency and moisture carrying capacity of westerly cyclonic systems (Hope 2006, Hope et al. 2006). Other modelling studies relate future warming to a decline in frequency and a poleward displacement of midlatitude cyclones (Yin 2005, Lambert \& Fyfe 2006). Any greenhouse-induced shift in weather patterns will affect the Tasmanian region, but direct extrapolation of these results is difficult due to the unique set of conditions in the Australian environment: its southernmost latitude, its heavily mountainous western highlands, and its reliance on both westerly and subtropical systems for its precipitation. Future conditions may best be examined using a modelling approach focusing on the island state.

Future Tasmanian climates have been examined in a previous modelling study (McInnes et al. 2004). The 


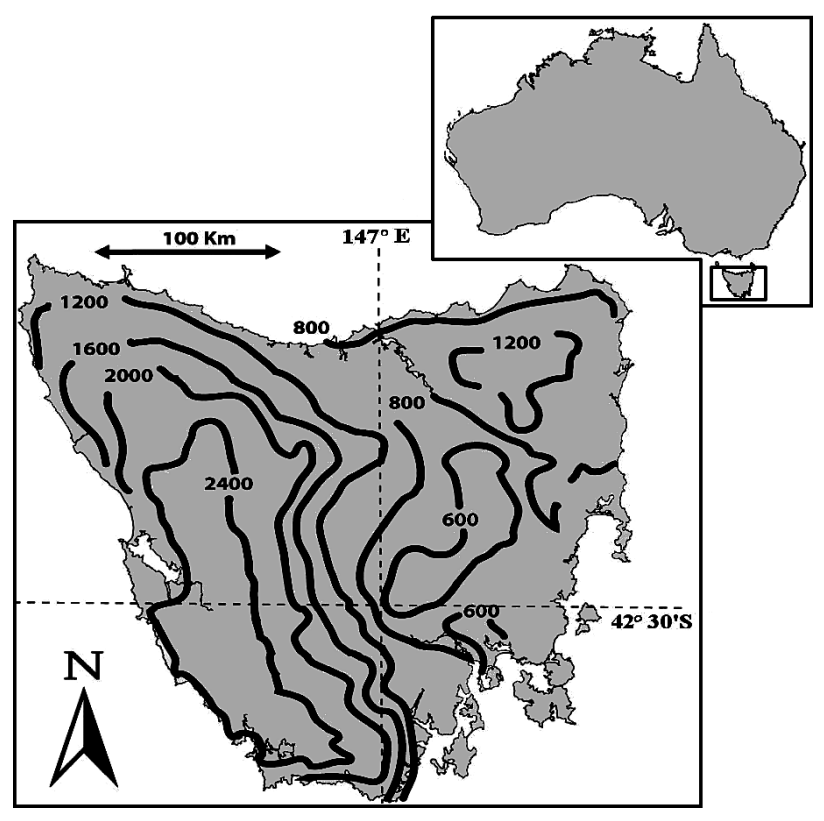

Fig. 1. Yearly precipitation $\left(\mathrm{mm} \mathrm{yr}^{-1}\right)$, Tasmania, Australia

authors used 22 model simulations from different centres around the world and assessed their ability to reproduce Australian conditions, the latter being determined by National Centers for Environmental Prediction (NCEP) Reanalysis data. Of the models examined, the $60 \mathrm{~km}$ resolution CSIRO ConformalCubic Atmospheric Model (CCAM) performed amongst the top 3 in terms of its low RMS error when estimating seasonal sea level pressure (SLP), surface air temperature, $10 \mathrm{~m}$ wind speed and precipitation. A second part of the study involved producing future changes in climate conditions for Tasmania using ensemble averages of the 12 best performing models.

Here we extend the above work by focusing on the water balance in Tasmania using detailed meteorological data collected for Tasmania to tune model output. The CCAM model tested above was considered most suitable given its good performance and high $60 \mathrm{~km}$ resolution in the Australian region. We used 'raw' model output for 2 distinct time periods - present (1975-2005) and future (2035-2065) - and transformed these data into a change in water balance (precipitation-evaporation) resulting from projected warming. The raw output of the basic weather variables (air temperature, specific humidity, pressure, precipitation, etc.) was modified in 2 ways. Precipitation $(P)$ was tuned by comparison with a detailed network of rain gauges available in Tasmania. This task gave a calibration factor that was applied to future precipitation. A second modification involved re-working the model raw data into estimates of potential evapotranspiration (PE) for the present. Model output was calibrated with respect to present PE estimated from weather records, and the second calibration factor was used to correct future PE estimates. Output data were subdivided into 4 seasons, and yearly and seasonal changes in $P, \mathrm{PE}$ and $(P-\mathrm{PE})$ were examined. The final section discusses likely changes in the circulation associated with these changes in the water balance.

\section{METHODOLOGY}

\subsection{CCAM model}

CCAM is formulated on the quasi-uniform conformalcubic grid, which is derived by projecting the panels of a cube onto the surface of the Earth. The model was originally developed as an atmospheric general circulation model (GCM) (McGregor \& Dix 2001), but for our study it is used as a regional climate model by applying the Schmidt (1977) transformation to produce variable resolution. In the configuration for the present simulation, the grid spacing over Australia is about $60 \mathrm{~km}$, increasing to about $700 \mathrm{~km}$ on the far side of the globe.

The primitive equations for mass, momentum and thermodynamics are solved at a time step of $20 \mathrm{~min}$, providing data at the spatial resolution detailed above (see previous paragraph) and over 18 vertical levels, with the lowest one at $38 \mathrm{~m}$ above the surface. Screenlevel and $10 \mathrm{~m}$ values are obtained using MoninObukhov theory for the layer below $38 \mathrm{~m}$ (McGregor et al. 1993). The model is embedded in the Mk3 CSIRO coupled atmosphere-ocean model, meaning that CCAM uses sea-surface temperatures, ice extent and far-field wind values provided on a twice-daily basis from this GCM. The CCAM winds are nudged each time step above $900 \mathrm{hPa}$ on the furthest grid panel by winds from the Mk 3 model, using an e-folding time of $24 \mathrm{~h}$; on the adjacent panels, the wind nudging gradually commences at about $2500 \mathrm{~km}$ from the Australian coastline; further details are provided by McGregor (2005). Fig. 2 shows the distribution of spatial bins used for the Tasmanian region.

The model run was started in 1960 and allowed to run continuously until 2100. Global $\mathrm{CO}_{2}$ concentrations were allowed to increase following a high $\mathrm{CO}_{2}$ consumption A2 scenario characterised by slow economic growth and continuously increasing world population. Two $30 \mathrm{yr}$ datasets were selected from this model run, the first one encompassing the years 1975-2005; the second 2035-2065. Data were written on a daily basis at 10:00 h local time, and included $24 \mathrm{~h}$ convective and total rainfall to $10: 00 \mathrm{~h}$, daily maximum, minimum and mean screen level air temperature, SLP and mixing ratio, $10 \mathrm{~m}$ wind speed and daily average surface net solar and net longwave radiation. 


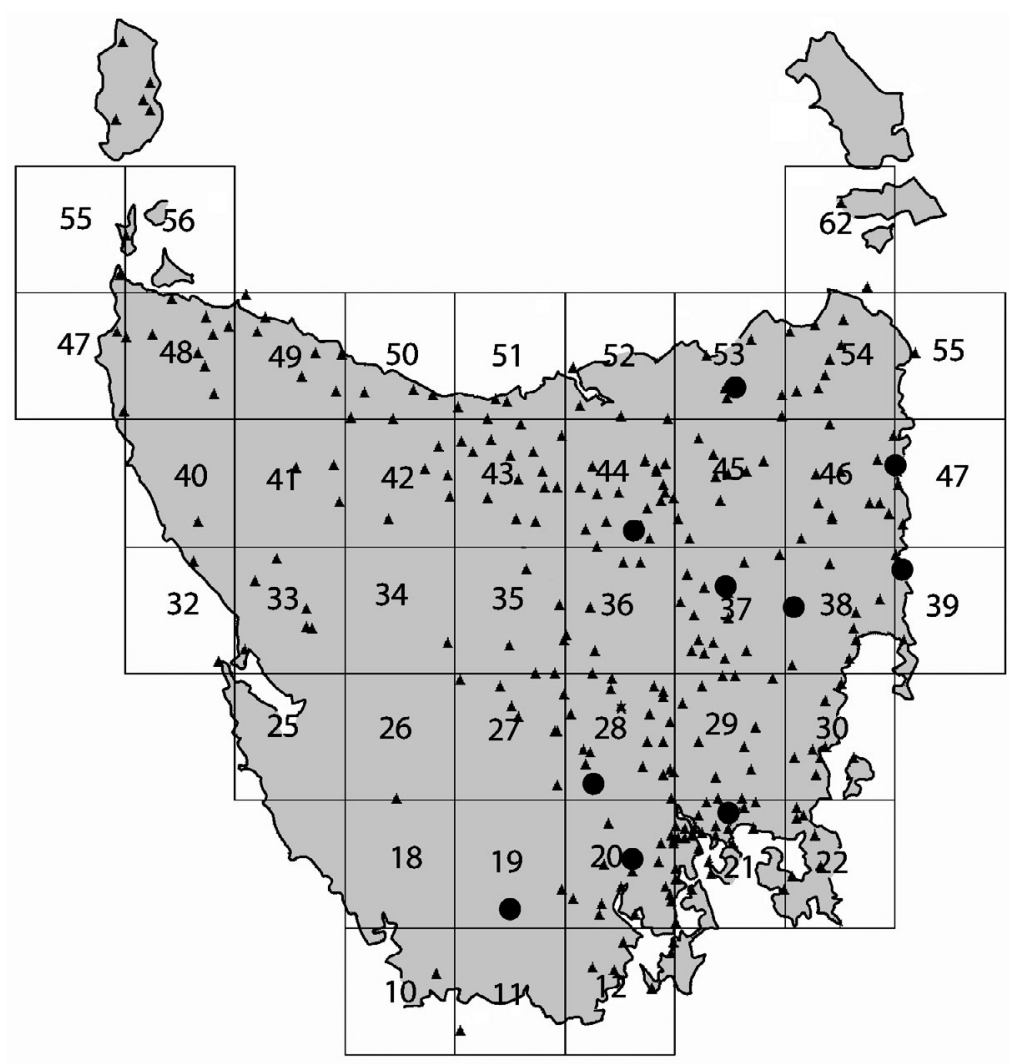

Fig. 2. Tasmanian study region. Numbered boxes: model output grid, each box $\sim 60 \times 60 \mathrm{~km}$.; $\mathbf{\Delta}$ : rainfall stations; $\bullet$ : more comprehensive stations used in evapotranspiration calculations

\subsection{Surface weather records used}

A total of 278 precipitation stations were used in this analysis (Fig. 2). Data were obtained as monthly totals (January 1975 to June 2003), seasonally averaged and stored in their respective bins, the latter being defined by the distance to the closest model grid point. Summer was defined as December to February, autumn as March to May, winter as June to August, and spring as September to November.

Additional meteorological data were obtained from weather stations in Tasmania for the calculation of PE. Data from a total of 10 stations were used (Fig. 2). They consisted of sunshine duration, pan evaporation, maximum and minimum air temperature, 09:00 $\mathrm{h}$ and 15:00 $\mathrm{h}$ air temperature, relative humidity, $10 \mathrm{~m}$ wind speed and SLP, all expressed as long-term monthly averages. As with the precipitation data, they were seasonally averaged and used for further analysis.

\subsection{Estimating present and future precipitation}

Model precipitation output, both present and future, were seasonally averaged and grouped into their respective spatial bins as were measured precipitation data. The 2 datasets formed the basis for the analysis. The model grid of $60 \mathrm{~km}$ resolution is somewhat coarse for direct comparison with station data. Hence seasonal precipitation data from surface weather stations were averaged in each model grid square and compared with seasonal model output for the same grid square. This procedure formed the basis of a linear regression between model and measured precipitation-one for each of the 4 seasons. The resulting regressions are then used to adjust present and future model data to a common base, that being of the present measured data (Fig. 3).

\subsection{Estimating PE}

Water loss by evaporation is an important component of the water balance, and in the present study several options were available. Model output produces actual evapotranspiration (AE) on a daily basis as well as volumetric soil moisture (SM) at 6 levels. However AE is very much linked to the local vegetation and SM characteristics (Davies \& Allen 1973, Monteith \& Unsworth 1990) and does not fully measure the potential of the surface to evaporate water. Use of SM changes to estimate water loss is also limited in that SM changes are also driven by local processes, and in addition there are further complexities such as surface and sub-surface run-off which affect SM but do not
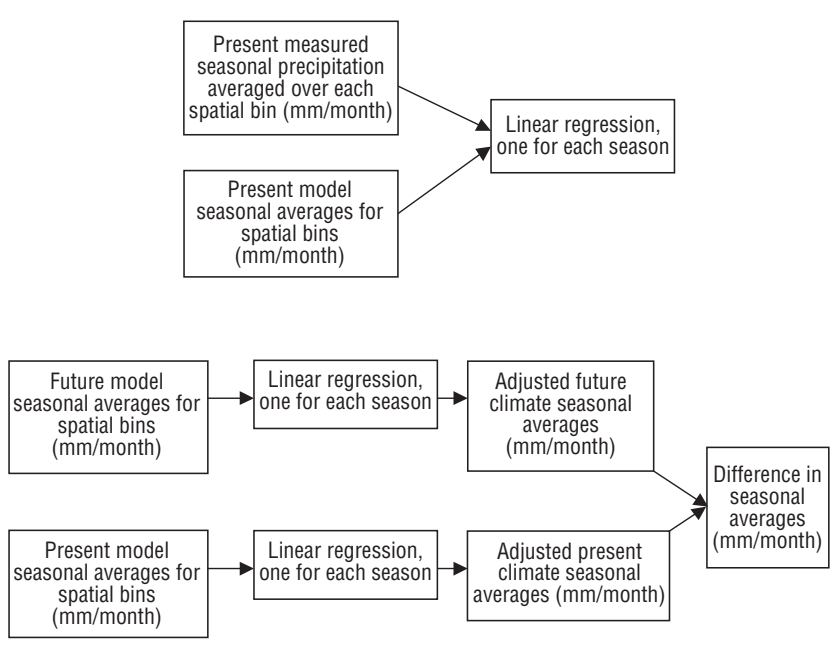

Fig. 3. Precipitation model. Linear regressions are used to adjust present and future model calculations to the measurement data base 
directly relate to evapotranspiration. For these reasons it was decided to use PE as it is a measure of the potential of the atmosphere to evaporate water when water is not limiting, it does not vary very much at the local scale, and it can be used to estimate AE or SM with a suitable hydrologic model.

The widely accepted Penman-Monteith model of evapotranspiration for a short grass surface was used in this study (Allen et al. 1998). Its advantages are that it has been tested over many different environments, and most importantly, for input it uses meteorological data collected from standard weather observations. The Penman-Monteith form of PE may be written as the sum of a radiation-dependent term and an aerodynamic or wind-dependent term, i.e.

$$
\mathrm{PE}=\frac{0.408 S\left(Q^{*}-Q_{\mathrm{G}}\right)+\gamma \frac{900}{T+273} u\left(e_{\mathrm{S}}-e_{\mathrm{A}}\right)}{S+\gamma(1+0.34 u)}
$$

with the PE in $\mathrm{mm} \mathrm{d}^{-1}, Q^{*}$ the net radiation $\left(\mathrm{MJ} \mathrm{m}^{-2}\right.$ $\left.\mathrm{d}^{-1}\right), Q_{\mathrm{G}}$ the soil heat flux $\left(\mathrm{MJ} \mathrm{m}^{-2} \mathrm{~d}^{-1}\right), e_{\mathrm{S}}$ and $e_{\mathrm{A}}$ the saturation and actual vapour pressure of the air respectively at $2 \mathrm{~m}$ height $(\mathrm{kPa}), T$ the daily mean air temperature at $2 \mathrm{~m}$ height $\left({ }^{\circ} \mathrm{C}\right), u$ the wind speed at $2 \mathrm{~m}$ height $\left(\mathrm{m} \mathrm{s}^{-1}\right), S$ the slope of the saturation vapour pressure/temperature curve $\left(\mathrm{kPa}{ }^{\circ} \mathrm{C}^{-1}\right)$, and $\gamma$ the psychrometric constant $\left(0.066 \mathrm{kPa}^{\circ} \mathrm{C}^{-1}\right)$.

Estimation of $\mathrm{PE}$ for short grass surface conditions might appear restrictive for this study, but there is no single representative surface type for the entire region. It is possible to assign different aerodynamic coefficients depending on surface types, but the choice of surface type is somewhat arbitrary, subject to complex spatial scale considerations (Running 1991), and dependent on land use changes that may have occurred between present and future. A preferred option is to use the original formulation derived for a short grass surface on the understanding that it is the potential of the atmosphere to evaporate water that is being studied, rather than a specific set of surface conditions.

Model data can be used to estimate seasonal averages of PE for each grid box as all the terms in Eq. (1), with the exception of soil heat flux $Q_{\mathrm{G}}$ are provided as model output. However $Q_{\mathrm{G}}$ is a small term (Allen et al. 1988). In this study we have taken seasonal and yearly $Q_{\mathrm{G}}$ to be zero.

PE was also estimated for the 10 Tasmanian stations that had suitable measured data as listed above. However there are no net radiation data $\left(Q^{*}\right)$, an important component of PE. To obtain this term, a regression was developed between maximum and actual sunshine duration and measured and extra-terrestrial global solar radiation using measured pyranometer data for Hobart Airport (Nunez 1978):

$$
\frac{K_{\mathrm{C}}}{K_{0}}=0.69 \frac{S}{S_{0}}+0.13
$$

where $K_{\mathrm{C}}$ and $K_{0}$ are the surface and extra-terrestrial monthly average of daily solar radiation $\left(\mathrm{MJ} \mathrm{m}^{-2} \mathrm{~d}^{-1}\right)$, and $S$ and $S_{0}$ are the actual and maximum possible (cloud-free) sunshine hours. The regression in Eq. (2), essentially built from Hobart airport records using simultaneous data on solar radiation and sunshine duration, gave a satisfactory performance with an $\mathrm{R}^{2}$ of 0.82 and a standard error of 0.009 for the 12-monthly average data. The regression was then used to estimate $K_{C}$ for the 10 stations that had sunshine duration data.

Incoming longwave radiation was calculated using the clear sky relationship of Swinbank (Oke 1987). The following formula was used which includes correction for cloud cover

$$
\begin{aligned}
& L_{0}=\left(9.36 \times 10^{-6}\right) \sigma T^{6} \\
& L_{\mathrm{C}}=L_{0}\left(1+0.29 \frac{S}{S_{0}}\right)
\end{aligned}
$$

where $L_{0}$ and $L_{\mathrm{C}}\left(\mathrm{W} \mathrm{m}^{-2}\right)$ are the clear- and cloudy-sky incoming longwave irradiance, $T$ is air temperature (expressed as Kelvin, K), $\sigma$ is the Stefan-Bolzmann constant, while $S$ and $S_{0}$, as mentioned earlier, are the actual and maximum possible sunshine duration. The expression for $L_{C}$ is an approximation that typifies a range of low cloud types experienced in Tasmania.

This analysis assumes that over a $24 \mathrm{~h}$ period, extremes of surface temperature balance out to give an average figure close to the mean screenlevel air temperature for the day (Nunez 1978). Using a mean surface emissivity of 0.95 , the outgoing longwave radiation from the surface $L_{\mathrm{U}}\left(\mathrm{W} \mathrm{m}^{-2}\right)$ may be estimated:

$$
L_{\mathrm{U}}=0.95 T^{4}+0.05 L_{\mathrm{C}}
$$

Pooling all these terms together, the net radiation $Q^{*}$ $\left(\mathrm{MJ} \mathrm{m}^{-2} \mathrm{~d}^{-1}\right)$ may be expressed as:

$$
\begin{aligned}
Q^{*} & =K_{\mathrm{C}}-0.18 K_{\mathrm{C}}+\left(L_{\mathrm{C}}-L_{\mathrm{U}}\right) 0.0864 \\
& =K_{\mathrm{C}}(1-0.18)+\left(L_{\mathrm{C}}-L_{\mathrm{U}}\right) 0.0864
\end{aligned}
$$

where a surface albedo of 0.18 has been used as regionally representative for Tasmania (Nunez et al. 1987). The number 0.0864 is a factor that converts $L_{U}$ and $L_{\mathrm{C}}$ in Eq. (4) from $\mathrm{W} \mathrm{m} \mathrm{m}^{-2}$ to $\mathrm{MJ} \mathrm{m}^{-2} \mathrm{~d}^{-1}$. Having obtained $Q^{*}, \mathrm{PE}$ in Eq. (1) may be obtained.

The following steps are carried out in the PE analysis (Fig. 4): (1) estimate PE on a monthly average basis using data for 10 Tasmanian stations; (2) compare PE from weather stations with model PE for present conditions and for the bin encompassing the weather station; (3) correction relations are obtained to adjust model data; (4) PE for future conditions are estimated using correction relationships developed in (3). 


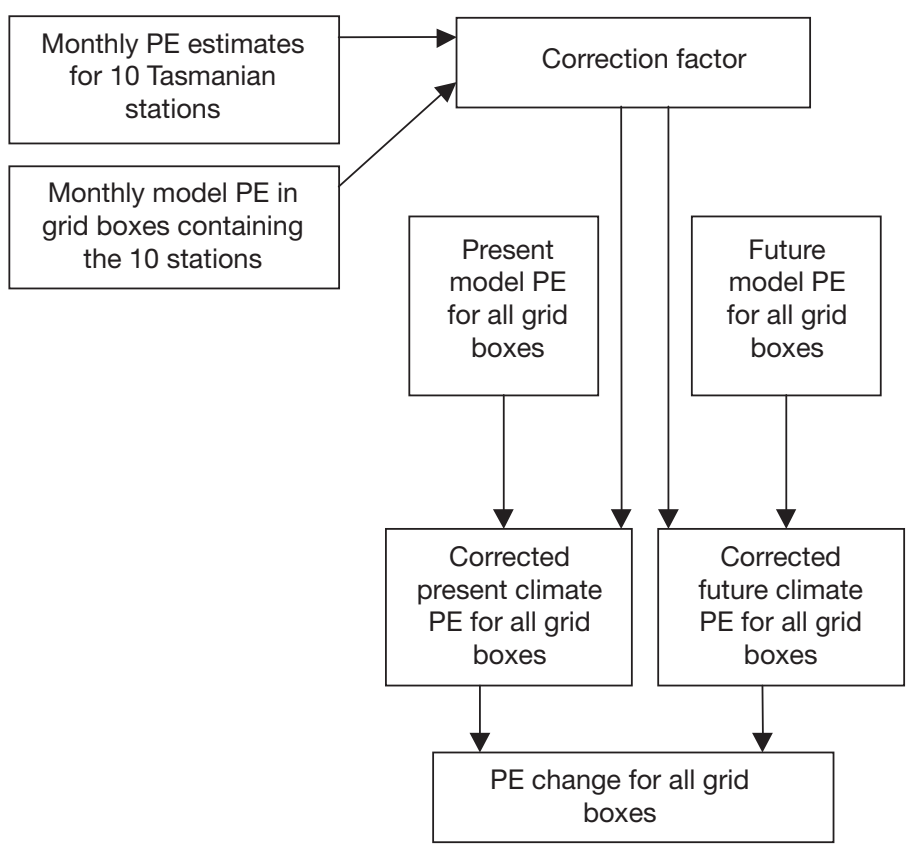

Fig. 4. Procedure followed to obtain potential evapotranspiration
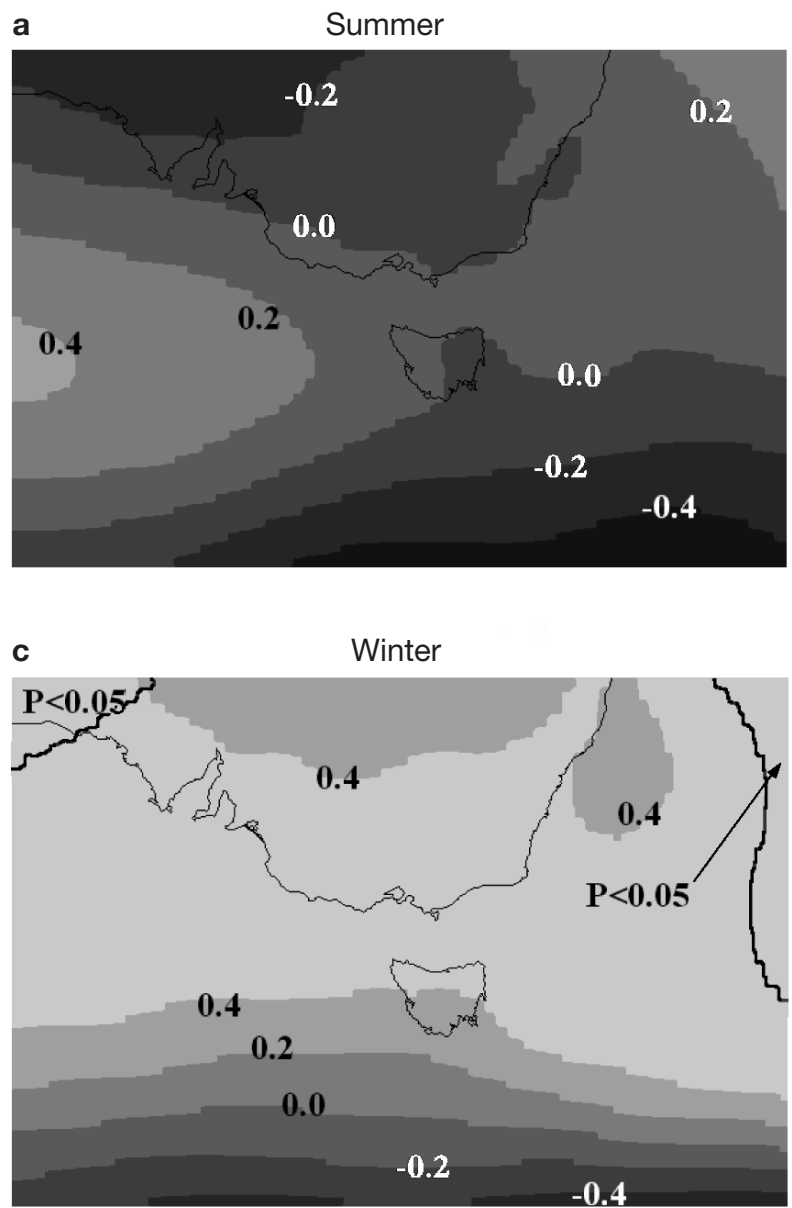

d

\section{RESULTS}

\subsection{Synoptic-scale changes}

Our analysis initially considers changes that have occurred at the synoptic scale covering the southeast Australian region, from 30.0 to $60.0^{\circ} \mathrm{S}$ and 130.0 to $160.0^{\circ} \mathrm{E}$. Two parameters are examined for their relevance in affecting synoptic systems in the region and, in particular, the PE component as defined in Eq. (1). Firstly, surface pressure changes, as evidenced by increased/decreased anticyclonicity, will enhance or hinder many of the mid-latitude frontal systems, as well as continental or east coast lows that bring precipitation to Tasmania (Gentilli 1972). As well as affecting the amount of precipitation, changes in the frequency of synoptic systems will also affect incident solar and longwave radiation (Eqs. 2 to 5). Secondly, surface wind speed was examined for its central role in affecting the magnitude of PE in Eq. (1).

Fig. 5 shows seasonal changes in CCAM SLP (future - present) obtained from the same $60 \mathrm{~km}$ dataset as
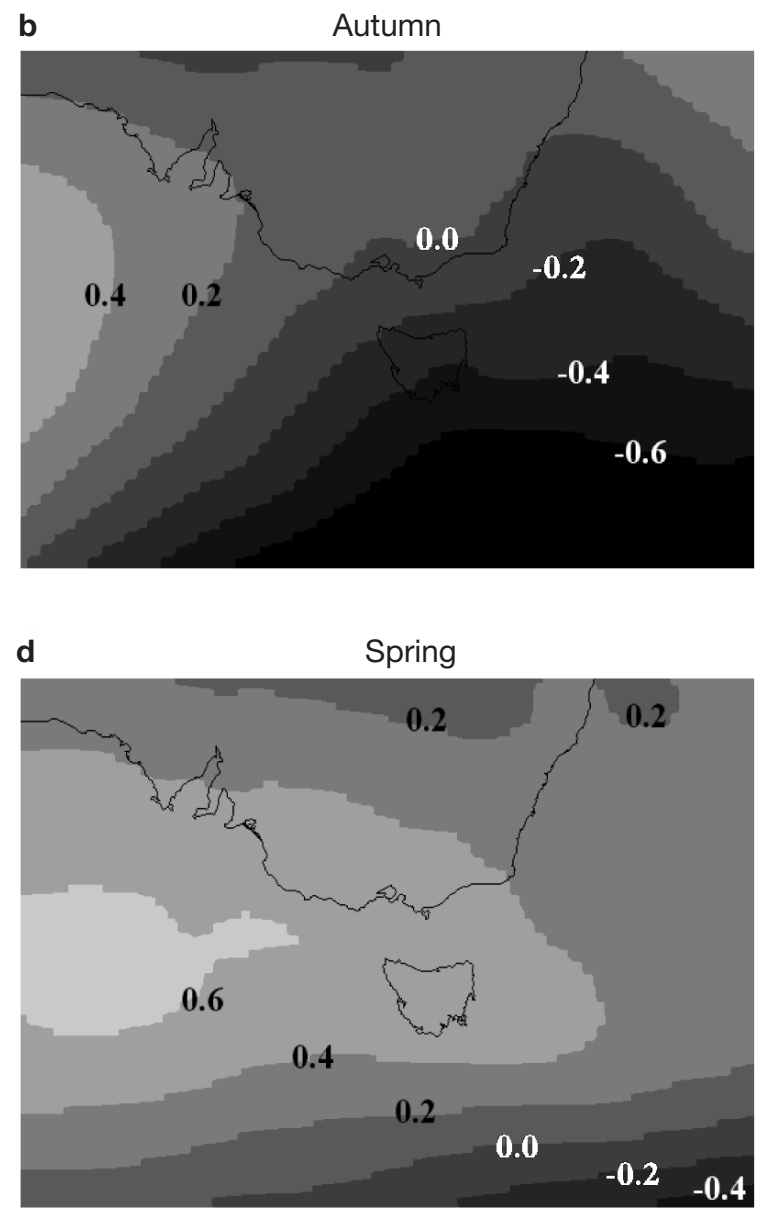

Fig. 5. Difference (future - present) of mean sea level pressure (hPa) using CCAM model output for the region $30.0-60.0^{\circ} \mathrm{S}$, 130.0-160. $0^{\circ}$ E. (a) Summer, (b) autumn, (c) winter, (d) spring. Thick lines: regions with $\mathrm{p} \leq 5 \%$ 
a

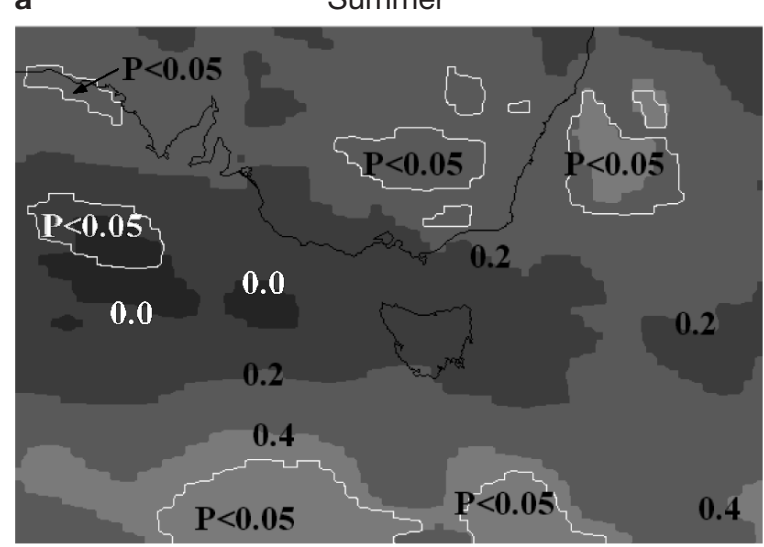

c

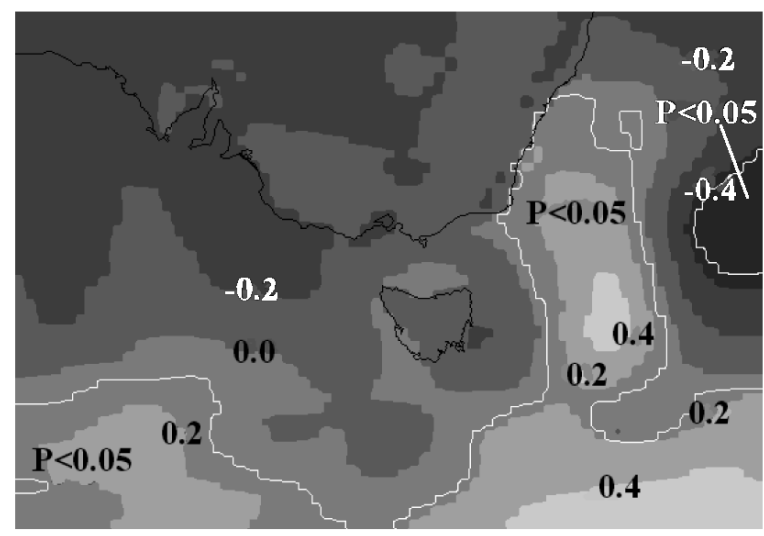

b

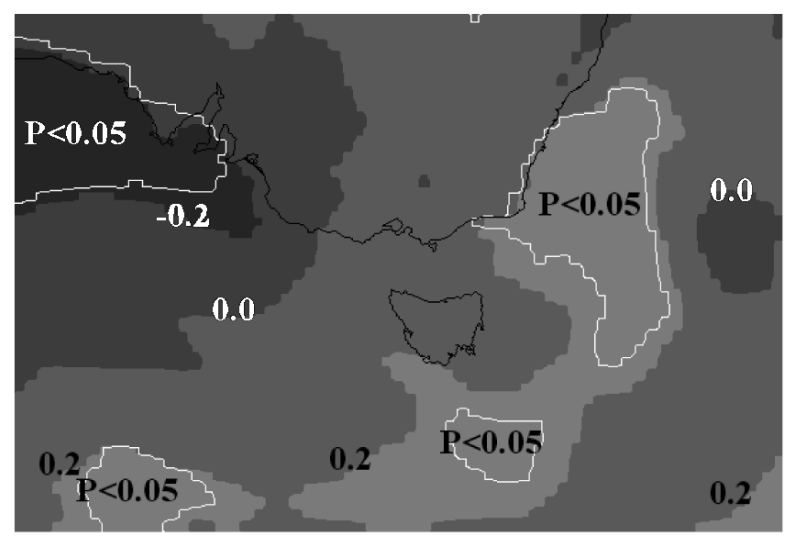

d

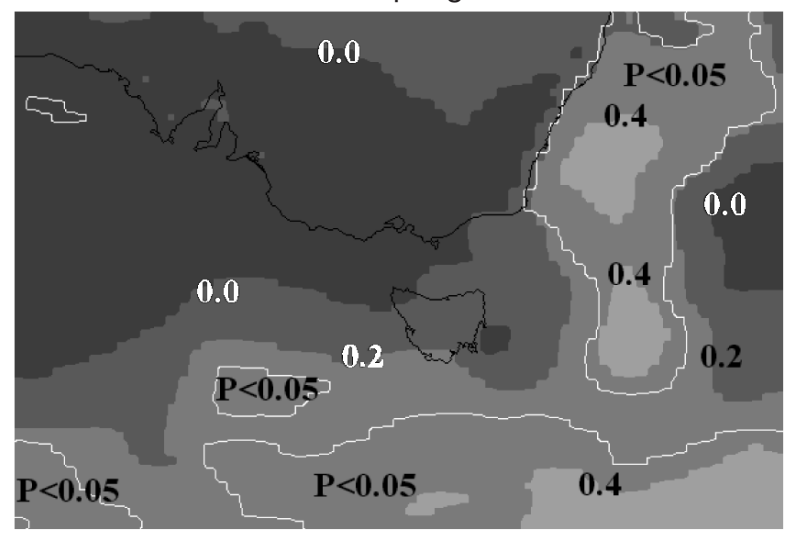

Fig. 6. Difference (future - present) of mean $10 \mathrm{~m}$ wind speed $\left(\mathrm{m} \mathrm{s}^{-1}\right)$ using CCAM model output for the region $30.0-60.0^{\circ} \mathrm{S}$; 130.0-160.0 E. (a) Summer, (b) autumn, (c) winter, (d) Spring. White lines: regions with $\mathrm{p} \leq 5 \%$

used in the Tasmanian analysis. Changes are positive (increasing pressure) in all seasons with the exception of autumn. Summer, autumn and winter feature intensifying high pressure regions over the Australian Bight, and in winter there is a large latitudinal band extending from northern Victoria to Tasmania with positive pressure changes of around $0.4 \mathrm{hPa}$. All 4 seasonal diagrams exhibit negative pressure changes at high latitudes.

Fig. 6 shows differences in mean seasonal $10 \mathrm{~m}$ wind speed (future - present) for the same region. Results show that all seasons except winter feature increasing wind speeds, although they are not statistically significant for the Tasmanian region. By contrast, the Tasman Sea region and latitudes south of Tasmania exhibit larger changes that are statistically significant. Increasing SLP over Tasmania (but decreasing southwards) will induce stronger pressure gradients, and this process is likely to be linked to stronger winds to the south of Tasmania.

In summary, the changes that are presented for Tasmania in Figs. $5 \& 6$ is one of increasing (albeit weak) anticyclonicity in all seasons except autumn, and weak but increasing wind speeds for all seasons. However, we note that none of the changes are significant at the $5 \%$ level over Tasmania. Thus the larger scale synoptic pattern would hint at decreasing to zero precipitation changes over Tasmania, on average, and increasing $\mathrm{PE}$ by virtue of decreasing cloud cover (increasing solar radiation) and increasing wind speed. A more detailed analysis described in the next sections presents likely changes in precipitation and $\mathrm{PE}$ for Tasmania.

\subsection{Precipitation changes}

Fig. 7 and Eq. (6a-d) present regressions between measured (MEAS) and modelled (MODEL) rainfall $(P)$ for the 38 spatial bins encompassing the Tasmanian region. Model data cover a larger range of values than measured, especially for winter. In general, model data are higher than measured in the western highlands but lower in the dry southeast. All 4 graphs exhibit a high 


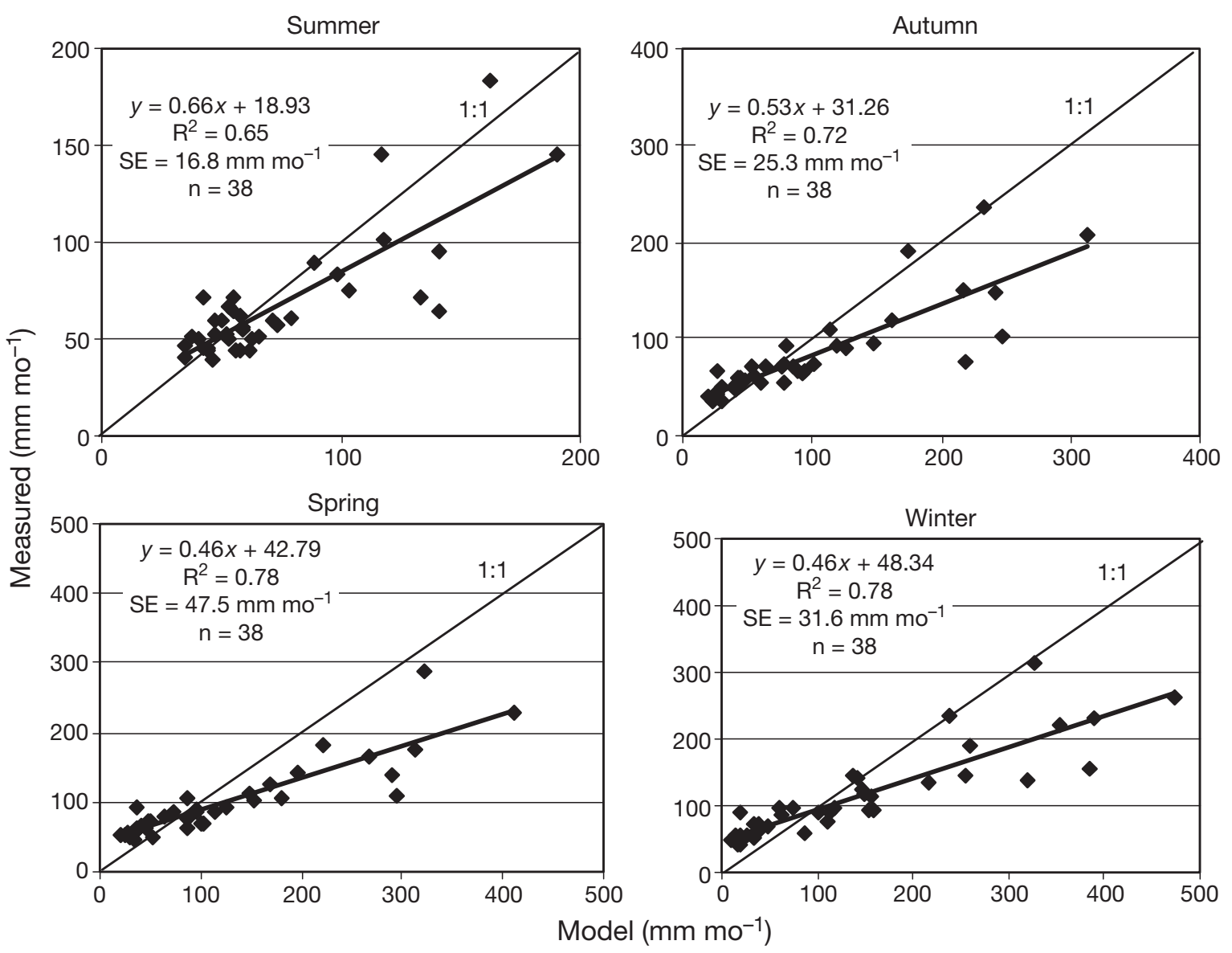

Fig. 7. Comparison of model estimates with present precipitation measurements. Points in graphs: seasonal averages in 38 grid bins over a 30 yr period. Note different scales on axes

correlation coefficient, indicating a linear transformation between measured and modelled datasets is possible.

$$
\begin{aligned}
& P_{\mathrm{MEAS}}=0.66 \mathrm{P}_{\mathrm{MODEL}}+18.93 \\
& \left(\mathrm{R}^{2}=0.65 ; \mathrm{SE}=16.8 ; \mathrm{n}=38 ; \text { summer }\right) \\
& P_{\mathrm{MEAS}}=0.53 \mathrm{P}_{\mathrm{MODEL}}+31.26 \\
& \left(\mathrm{R}^{2}=0.72 ; \mathrm{SE}=25.3 ; \mathrm{n}=38 ; \text { autumn }\right) \\
& P_{\mathrm{MEAS}}=0.46 \mathrm{P}_{\mathrm{MODEL}}+48.37 \\
& \left(\mathrm{R}^{2}=0.78 ; \mathrm{SE}=31.6 ; \mathrm{n}=38 ; \text { winter }\right) \\
& P_{\mathrm{MEAS}}=0.46 \mathrm{P}_{\mathrm{MODEL}}+42.79 \\
& \left(\mathrm{R}^{2}=0.78 ; \mathrm{SE}=47.5 ; \mathrm{n}=38 ; \text { spring }\right)
\end{aligned}
$$

These equations are then used to transform model precipitation into a tuned database corresponding to measurements. The precipitation maps are shown in Fig. 8. Measured precipitation data which have been grouped into spatial bins, are shown in Fig. 8a,c,e,g. There are no regular precipitation stations in the largely uninhabited southwestern Tasmania, where data have been left blank. During winter, frontal systems dominate, precipitation is high in the western highlands and there are strong east-west gradients related to rain shadow effects as the moist westerly air masses descend into the drier midlands and east coast (Fig. 8e). In summer, subtropical high pressure systems move south and bring drier and more settled conditions across the state (Fig. 8a).

Model estimates show drier conditions in summer along the eastern half of Tasmania and along the east coast in autumn (Fig. 8b,d). By contrast, greater precipitation is exhibited in the western half for future winters (Fig. 8f). Precipitation is expected to drop in future springs, with maximum decreases along the western highlands (Fig. 8h).

\subsection{PE changes}

Eq. (1) was applied to the 10 Tasmanian weather stations with suitable long-term monthly data. Results are plotted against long-term pan evaporation measured at the same stations (Fig. 9a). Both datasets follow closely the 1:1 line above $2 \mathrm{~mm} \mathrm{~d}^{-1}$. Below this value they tend to diverge. Pan evaporation never quite reaches zero, whilst $\mathrm{PE}$ does reach it and in fact goes 


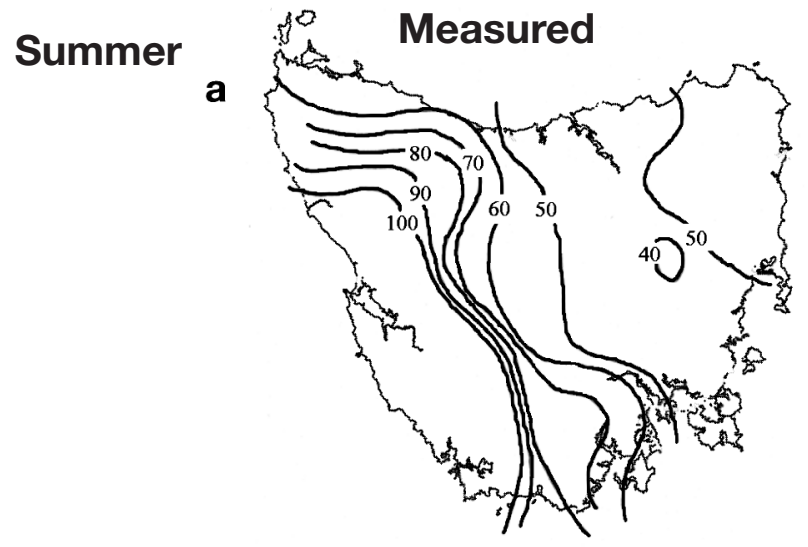

b
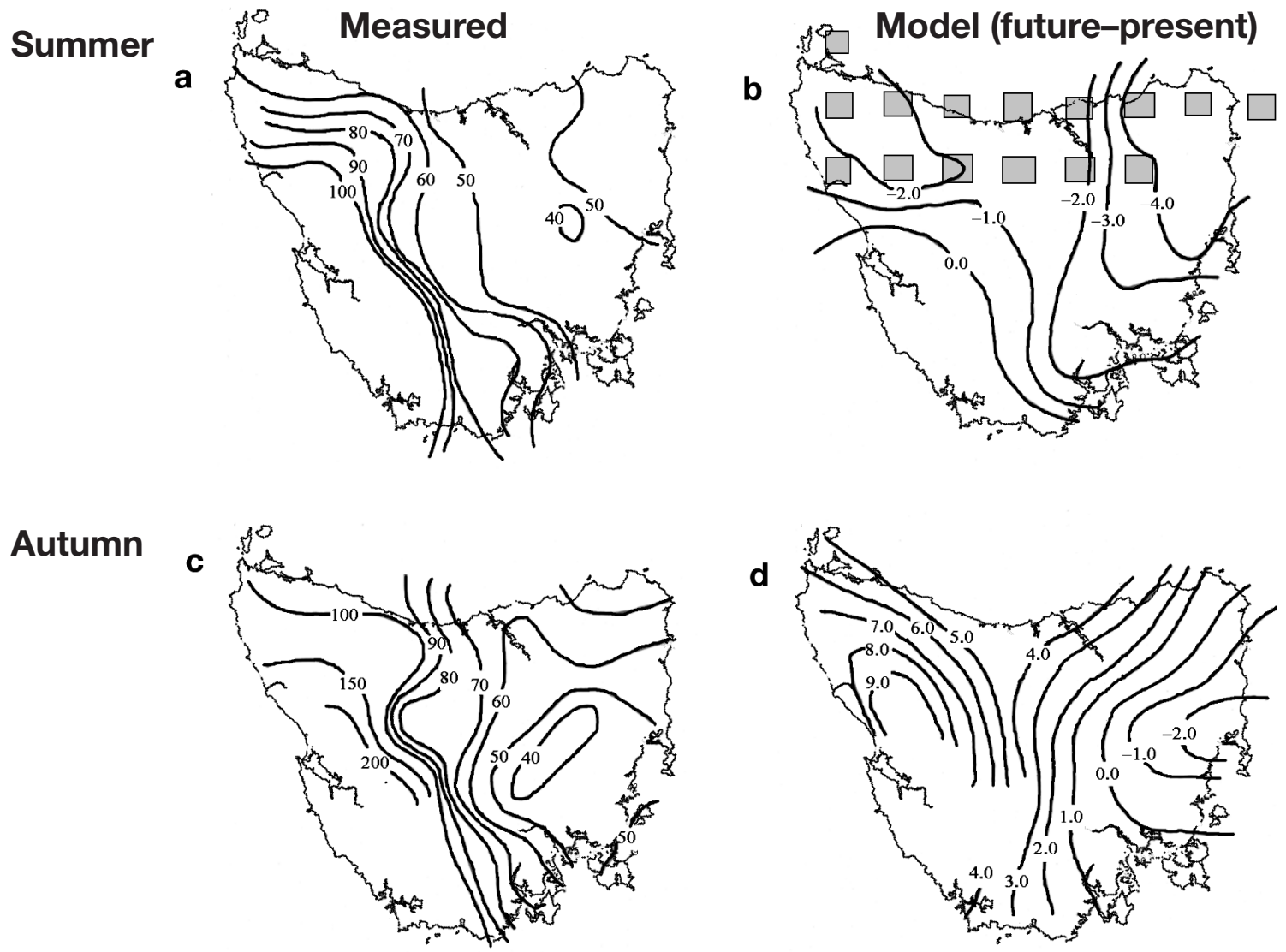

Winter
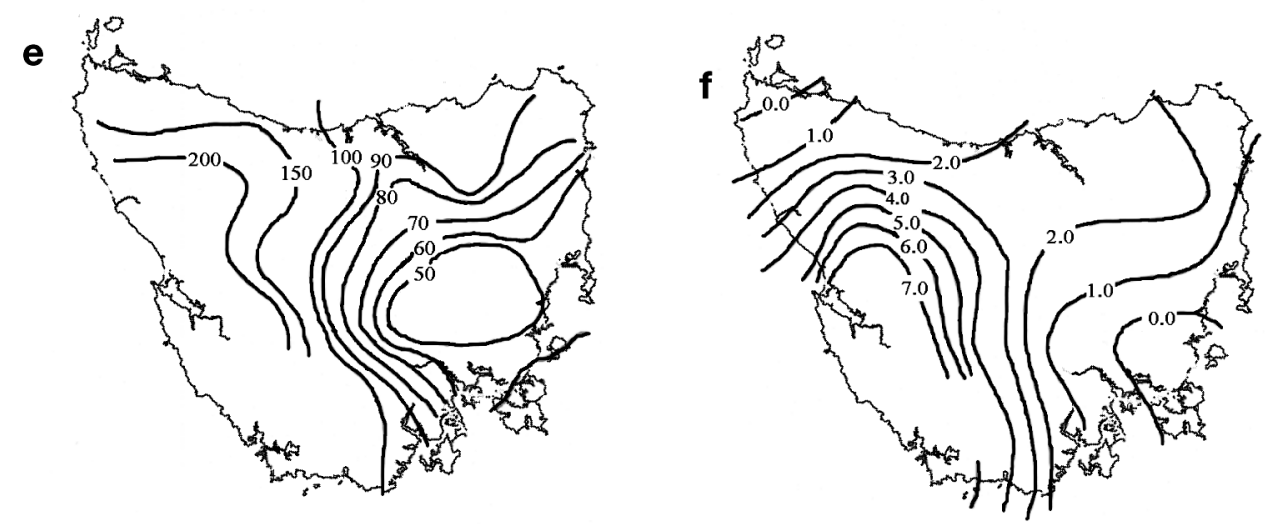

Spring
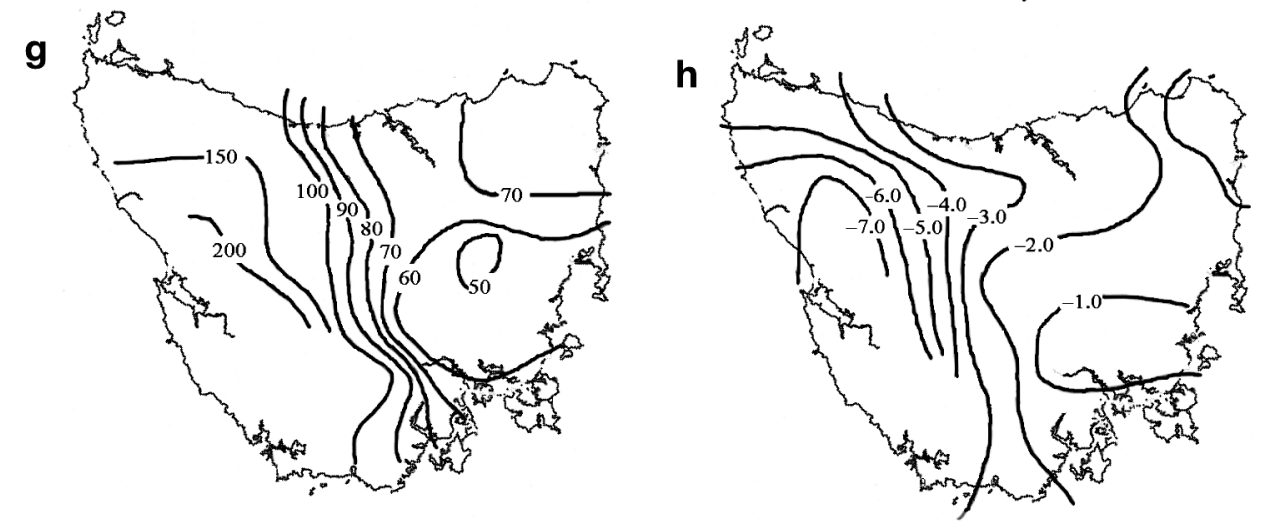

Fig. 8. Seasonal precipitation $\left(\mathrm{mm} \mathrm{mo}^{-1}\right)$ using measured data along with model estimates of future changes. Isolines are constructed from measured data that have been grouped into their respective bins. Grey squares: changes with confidence intervals of $95 \%$ 

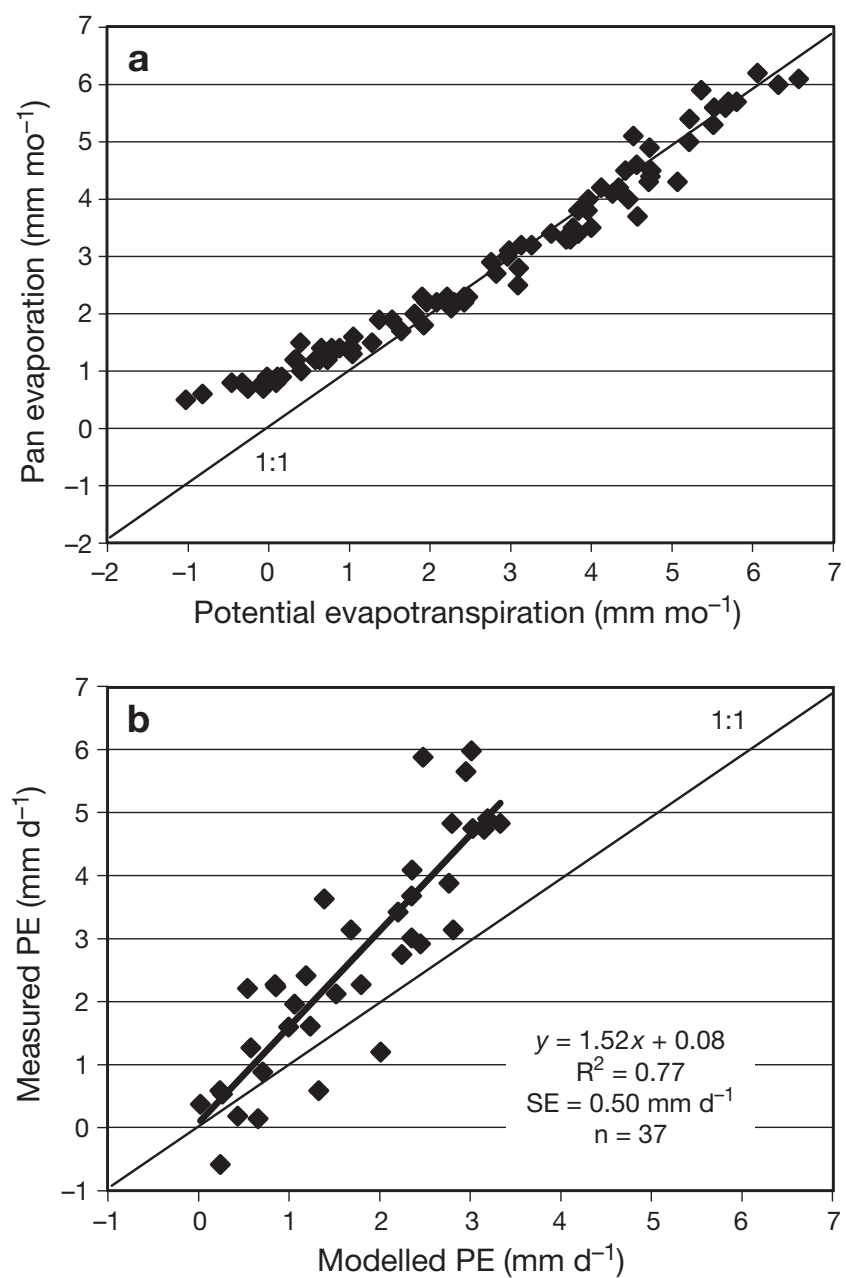

Fig. 9. (a) Long-term monthly pan evaporation vs. potential evapotranspiration for 10 stations in Tasmania using measured meteorological data. (b) Long-term potential evaporation using CCAM data for grids containing 10 stations vs potential evapotranspiration using meteorological data from the same stations

negative. It is likely that at these low values, mostly attained in the western highlands, small-scale advection dominates in the vicinity of the evaporating pan. The corresponding $\mathrm{PE}$ values continue to decrease towards zero and become slightly negative in very cloudy environments in mid-winter. The PenmanMonteith estimate is likely to be a more realistic representation of PE than pan evaporation in this low evaporation range. The Penman-Monteith model is tuned to give PE over extensive areas with no advection. As winter approaches net radiation will approach zero or be slightly negative, and so will PE. For practical purposes in this study, PE was taken to be zero when the model result gave negative values.

A test was then performed to observe how well CCAM estimated PE when compared with the 10 sta- tions containing weather data. Fig. 9b compares the 2 datasets, where the CCAM estimate is calculated at the grid box containing the weather station. The results are as follows:

$\mathrm{PE}_{\mathrm{MEAS}}=1.52 \mathrm{PE}_{\mathrm{MODEL}}+0.8$

$\mathrm{R}^{2}=0.77 ; \mathrm{SE}$ of regression $=0.50 \mathrm{~mm} \mathrm{~d}^{-1} ; \mathrm{n}=37$

Overall, PE $\left(\mathrm{mm} \mathrm{d}^{-1}\right)$ derived from the CCAM output gives estimates that are too small compared with measured PE. The 2 sets are, however, well correlated with an explained variance $\left(\mathrm{R}^{2}\right)$ of 0.77 . The procedure followed was to correct all CCAM-derived values by the above relationship.

$\mathrm{PE}$ for the 4 seasons and associated changes are shown in Fig. 10. The results show highest values during summer (Fig. 10a), which is expected, as it is mainly driven by radiation and to a lesser extent humidity deficits and wind speed. Maxima of $>160 \mathrm{~mm}$ $\mathrm{mo}^{-1}$ are obtained in the drier and sunnier eastern sector and minima are obtained along the west coast $\left(<80 \mathrm{~mm} \mathrm{mo}^{-1}\right)$. The pattern is repeated in autumn (Fig. 10c), but with lower values. There is very little net radiation in winter and values are close to zero in the central plateau (Fig. 10e). Solar radiation increases in spring, so that springtime PE is close to the summer values (Fig. 10g).

Changes in PE are greatest in summer, with values $>8 \mathrm{~mm} \mathrm{mo}^{-1}$ along the midland and in the southeastern region of the state (Fig. 10b). Estimated changes in all months except winter are strongly significant. In autumn (Fig. 10d) PE is close to zero in the southwest, and maxima are along the east coast with values of $>5 \mathrm{~mm} \mathrm{mo}^{-1}$. Very few changes are seen in winter (Fig. 10f), and in spring the east coast maxima are reestablished.

\subsection{Water storage changes}

In this section we estimate yearly storage as $P-P E$, which are calculated on an annual basis. Fig. 11 shows present storage and expected changes for Tasmania using the tuned model precipitation and tuned model estimates of PE. The western half of the state experiences large gains, indicating that in the west this excess storage is used up as underground and surface runoff. By contrast the eastern half has a deficit, and in the case of a lake or dam this deficit must be replenished by stream flow or underground transport. Decreases in net storage, Fig. 11b, are quite substantial, reaching maximum values of just over $80 \mathrm{~mm} \mathrm{yr}^{-1}$ along the east coast. Storage changes are negative throughout Tasmania with the exception of the western region. 

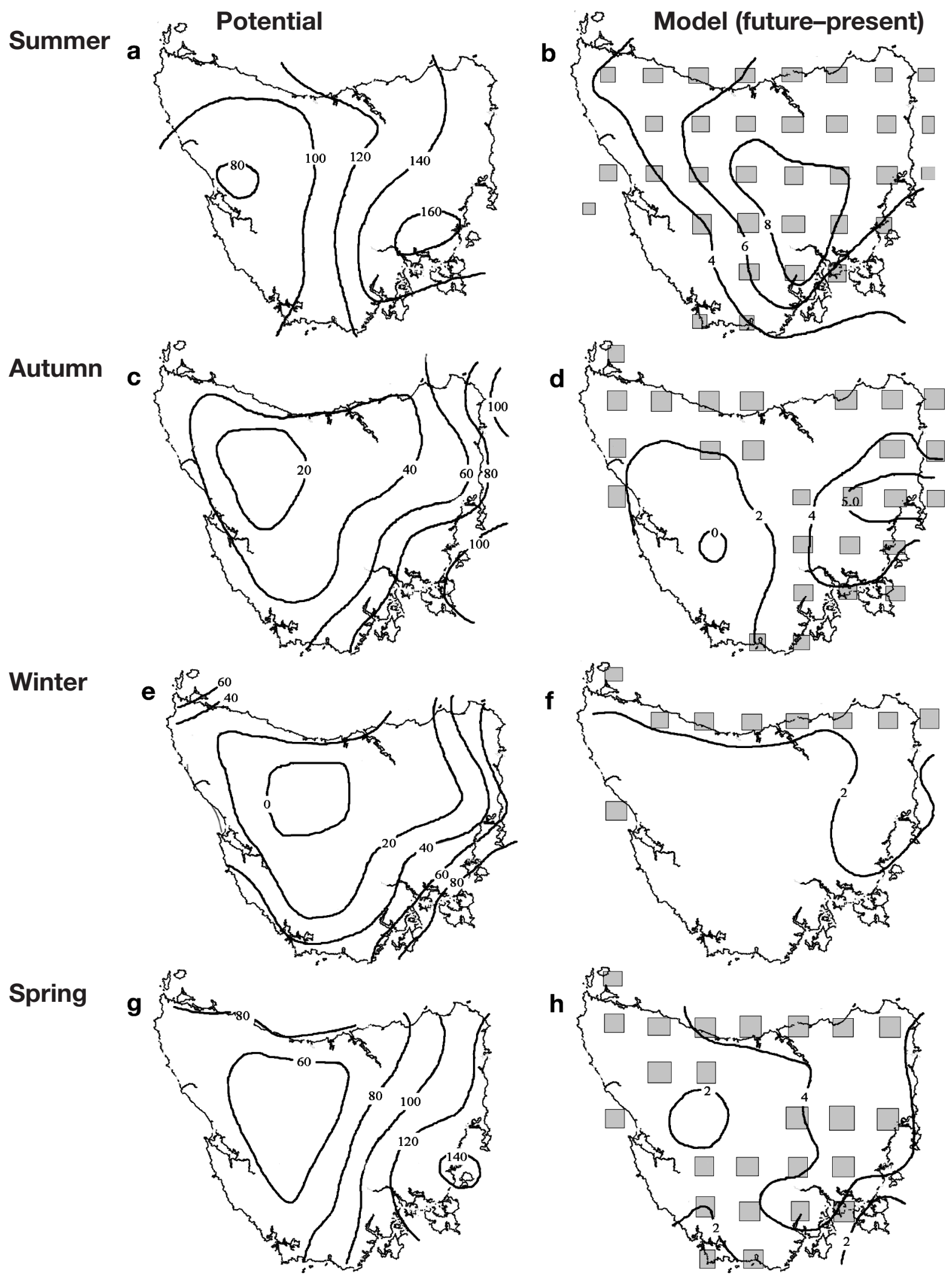

Fig. 10. Tuned model potential evapotranspiration $\left(\mathrm{mm} \mathrm{mo}^{-1}\right)$ for (a) summer, (b) autumn, (c) winter and (d) spring. Calculated potential evapotranspiration changes for (b) summer, (d) autumn, (f) winter and (h) spring. Grey squares: changes with confidence intervals of $95 \%$ 
Fig. 11. (a) Yearly storage $(P-$ $\left.\mathrm{PE}, \mathrm{mm} \mathrm{yr}^{-1}\right)$. (b) Change in yearly storage: $(P-\mathrm{PE})$ future minus $(P-\mathrm{PE})$ present $\left(\mathrm{mm} \mathrm{yr}^{-1}\right)$
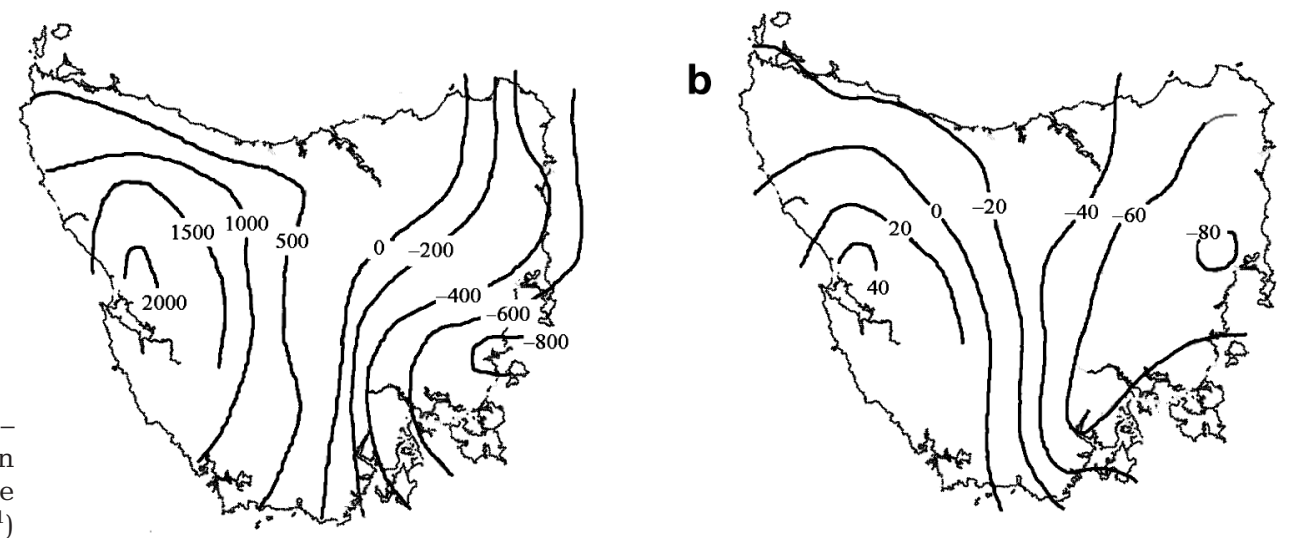

\section{DISCUSSION}

Changes in water storage involve not only changes in precipitation, but changes in surface evapotranspiration and the energy balance as well. To encompass all these processes, this study has not only examined precipitation, but has developed an evapotranspiration relationship which can be tested within the framework of the CCAM model. Central to the study are the likely changes in synoptic systems for the study area. Our results, showing weak but increasing SLPs, are in agreement with the studies of Hope (2006), Hope et al. (2006) and Li et al. (2005) which report increasing anticyclonic behaviour for southwest Australia under future scenarios.

Results of the analysis for Tasmania show a small lowering of the precipitation during summer and autumn along the east coast, southeast and midlands, with maximum lowering along the north and central regions of the east coast. However, decreases are small, with maximum decreases in summer of $4.5 \mathrm{~mm} \mathrm{mo}^{-1}$, which is a $9 \%$ drop in summer precipitation. Similarly, maximum decreases in autumn of $2.4 \mathrm{~mm} \mathrm{mo}^{-1}$ translate to a $5 \%$ decrease. These small changes differ from those reported using ensemble model predictions for West Australia (Hope 2006). However Tasmania is a considerable distance to the south of West Australia, so that a poleward displacement of storm tracks as reported by Yin (2005) might still influence Tasmanian precipitation.

Precipitation is not the only term in the water balance and PE is just as important as it affects loss from the surface to the atmosphere. Future PE shows increases in all seasons, with absolute increases being largest in summer. A PE increase of $7.6 \mathrm{~mm} \mathrm{mo}^{-1}$ is estimated for summer in the same bin (46) as the one reporting a maximum precipitation loss. Adding a summer precipitation drop of $4.5 \mathrm{~mm} \mathrm{mo}^{-1}$ for this grid bin, a total extra water loss of $12.1 \mathrm{~mm} \mathrm{mo}^{-1}$ is estimated. This is slightly less than 3 extra days of PE loss per month, or a drop of $19.4 \%$ in available liquid water that is estimated from present measured precipitation for summer (62.3 $\mathrm{mm} \mathrm{mo}^{-1}$ at bin 46$)$. Clearly these figures are important for their potential impact. Table 1 shows these statistics for the 10 bins located in the east coast and midlands (see also Fig. 2).

Table 1. Water balance statistics $\left(\mathrm{mm} \mathrm{mo}^{-1}\right)$ for 10 bins near the east coast. Difference values are calculated by subtracting present from future (future - present). Data for winter shows no significant change, and has been omitted from the table.

$P$ : present precipitation; PE: potential evapotranspiration

\begin{tabular}{|c|c|c|c|c|c|}
\hline Bin & $P$ & $\Delta P$ & $\Delta(\mathrm{PE})$ & $\Delta(P-\mathrm{PE})$ & {$[\Delta(P-\mathrm{PE}) / P] \times 100$} \\
\hline \multicolumn{6}{|c|}{ Summer } \\
\hline 21 & 50.8 & -2.0 & 5.4 & -7.4 & -14.6 \\
\hline 22 & 60.0 & -1.9 & 3.6 & -5.5 & -9.2 \\
\hline 29 & 46.6 & -2.8 & 8.3 & -11.1 & -23.8 \\
\hline 30 & 49.6 & -2.6 & 6.0 & -8.5 & -17.2 \\
\hline 37 & 39.0 & -3.4 & 8.2 & -11.6 & -29.8 \\
\hline 38 & 50.1 & -4.4 & 7.6 & -11.9 & -23.8 \\
\hline 45 & 54.6 & -3.4 & 7.0 & -10.4 & -19.0 \\
\hline 46 & 62.3 & -4.5 & 7.6 & -12.1 & -19.4 \\
\hline 53 & 49.1 & -4.0 & 6.3 & -10.3 & -21.0 \\
\hline 54 & 52.2 & -3.9 & 6.7 & -10.6 & -20.4 \\
\hline \multicolumn{6}{|c|}{ Autumn } \\
\hline 21 & 45.4 & 0.5 & 3.8 & -3.3 & -7.2 \\
\hline 22 & 59.4 & 0.6 & 3.7 & -3.1 & -5.2 \\
\hline 29 & 41.5 & -0.6 & 5.1 & -5.7 & -13.7 \\
\hline 30 & 43.4 & -0.7 & 4.8 & -5.5 & -12.6 \\
\hline 37 & 35.5 & -1.1 & 5.0 & -6.0 & -17.0 \\
\hline 38 & 49.6 & -2.1 & 5.5 & -7.6 & -15.3 \\
\hline 45 & 61.4 & 1.7 & 3.5 & -1.8 & -3.0 \\
\hline 46 & 59.1 & -0.1 & 4.3 & -4.4 & -7.5 \\
\hline 53 & 72.0 & 3.9 & 3.1 & 0.8 & 1.1 \\
\hline 54 & 70.8 & 0.8 & 3.7 & -2.9 & -4.1 \\
\hline \multicolumn{6}{|c|}{ Spring } \\
\hline 21 & 57.4 & -1.0 & 4.2 & -5.1 & -9.0 \\
\hline 22 & 66.3 & -1.4 & 1.7 & -3.1 & -4.7 \\
\hline 29 & 52.2 & -0.5 & 5.0 & -5.5 & -10.5 \\
\hline 30 & 52.8 & -0.7 & 3.7 & -4.4 & -8.3 \\
\hline 37 & 47.9 & -1.0 & 5.2 & -6.3 & -13.1 \\
\hline 38 & 56.3 & -1.1 & 5.5 & -6.6 & -11.7 \\
\hline 45 & 81.0 & -2.3 & 4.7 & -7.0 & -8.7 \\
\hline 46 & 74.2 & -1.6 & 5.2 & -6.8 & -9.2 \\
\hline 53 & 75.8 & -1.8 & 4.8 & -6.6 & -8.8 \\
\hline 54 & 72.8 & -0.5 & 4.5 & -5.0 & -6.8 \\
\hline
\end{tabular}


A further explanation of the physical significance of the $P-P E$ deficit is needed. As discussed previously, PE refers to water loss from the surface when water is not limiting. In terms of water loss from a water body such as a lake or dam, these figures are a good indicator of future stress. Similarly, the figures shown in the present study are applicable in the case of intensive agriculture where a particular crop is kept well irrigated at near field capacity. The $P-P E$ deficit is interpreted as the amount of liquid water that must be supplied to the crop to keep it at field capacity. Changes in $P$ - PE between future and present may be interpreted as the extra irrigation needed to keep conditions at the same field capacity level as today.

However $P$ - PE figures do not represent the resultant changes in soil storage. As SM drops, evapotranspiration from crops drops below the potential rate due to stomatal closing, and in bare soils hydraulic conductivity loses efficiency as soils dry. Although AE can be obtained directly from the CCAM results, no field data is available for validation and/or tuning. Therefore the SM or AE terms have not been examined.

The resultant trends are not totally unexpected. Higher SLPs (Fig. 5) will increase blocking in the region, therefore causing the cut-off lows and east coast low pressure systems to travel elsewhere (Yin 2005). These systems dominate rainfall in the midland and east coast of Tasmania (Gentilli 1972), therefore their absence will essentially create drier conditions.

In selecting a 'future' scenario for Tasmania, a decision was made to take a time-slice of the model output covering the years 2035-2065. This represents a time period centred $60 \mathrm{yr}$ from the present slice which is still close enough in time for planning strategies to be useful. It is important to keep in mind that the present models indicate likely trends rather than defining statistics with absolute certainty.

Our water balance results are in broad agreement with the Tasmanian study by McInnes et al. (2004). Nine out of the 12 GCMs that they examined (including the CCAM used in the present study, albeit unmodified in their study) showed decreasing summer precipitation per ${ }^{\circ} \mathrm{C}$ of warming. In winter, 9 out of the 12 stations exhibit higher precipitation, which agrees with our study. When all twelve models are examined for the same time period as in our study, increases in summer PE range from 1 to $9 \%$ for the entire island. Our results presented here fall well within the middle of this range, although our autumn and winter evaporation changes are at the lower end of their reported range.

Future studies which examine future water resources should include PE in their analyses. Other environments may also experience small changes in precipitation, but increased evapotranspiration may be suffi- cient to tip the water storage into a serious deficit. Predicted increases in air temperature will increase the capacity of the atmosphere to hold moisture, and assuming a constant or small change in absolute humidity, will increase the aerodynamic component of the evapotranspiration equation. Increases in solar radiation resulting from a drying environment will further enhance the potential for water loss. Ultimately these evaporation scenarios are based on the capacity of GCMs to adequately predict the surface radiation and energy balance. This is an important goal that should be examined further in future studies.

Acknowledgements. Kim Nguyen of the CSIRO Marine and Atmospheric Research extracted the CCAM model data used in this report. The authors are grateful to Professor Bill Budd for his valuable comments and suggestions. We are very grateful to Darren Turner who has been very helpful in processing the massive amounts of data involved. This work was supported by a grant from the Tasmanian Department of Primary Industries, Water and Environment. The CSIRO component of the work also received support from the Australian Greenhouse Office.

\section{LITERATURE CITED}

Allen RG, Pereira LS, Raes D, Smith M (1998) Crop evapotranspiration: guidelines for computing cropwater requirements. FAO Irrigation and Drainage Paper 56, Food and Agriculture Organization of the United Nations, Rome

Davies JA, Allen CD (1973) Equilibrium, potential and actual evaporation from cropped surfaces in southern Ontario. J Appl Meteorol 12:331-338

Gentilli J (1972) Australian climate patterns. Nelson, Melbourne

Hope PK (2006) Projected future changes in synoptic systems influencing southwest Western Australia. Clim Dyn 26:765-780

Hope PK, Drosdowsky W, Nicholls N (2006) Shifts in the synoptic systems influencing southwest Western Australia. Clim Dyn 26:751-764

IPCC (2001) Climate change 2001: the scientific basis. Intergovernmental Panel on Climate Change, UNEP/WMO, Cambridge University Press, Cambridge

Lambert SJ, Fyfe JC (2006) Changes in winter cyclone frequencies and strengths simulated in enhanced greenhouse warming experiments: results from the models participating in the IPCC diagnostic exercise. Clim Dyn 26:713-728

Li F, Chambers LE, Nicholls N (2005) Relationships between rainfall in the southwest of Western Australia and nearglobal patterns of sea-surface temperature and mean sealevel pressure variability. Aust Meteorol Mag 54:23-34

McGregor JL (2005) C-CAM: geometric aspects and dynamical formulation [electronic publication]. Technical Paper No. 70, CSIRO Atmospheric Research, Aspendale. Available at: www.cmar.csiro.au/e-print/open/mcgregor_ 2005a.pdf

McGregor JL, Dix MR (2001) The CSIRO conformal-cubic atmospheric GCM. In: Hodnett PF (ed) IUTAM symposium on advances in mathematical modeling of atmosphere and ocean dynamics. Kluwer, Dordrecht, p 197-202 
McGregor JL, Gordon HB, Watterson IG, Dix MR, Rotstayn LD (1993) The CSIRO 9-level atmospheric general circulation model. Technical Paper No. 26, CSIRO Division of Atmospheric Research, Aspendale. Available at: www. hydro.com.au/home/Energy/Climate+Change.htm

McInnes KL, Bathols J, Page C, Suppiah R, Whetton PH (2004) Climate change in Tasmania. CSIRO Climate Impact Group report to Hydro Tasmania, CSIRO Atmospheric Research, Aspendale.Available at: www.hydro.com.au/home/Energy/ Climate+Change.htm

Monteith JL, Unsworth M (1990) Principles of environmental physics. Edward Arnold, London

Nunez M (1978) The radiation index of dryness in Tasmania. Aust Geog Studies 16:126-135

Editorial responsibility: Gregory Jones, Ashland, Oregon, USA
Nunez M, Skirving WJ, Viney NR (1987) A technique for estimating surface albedos using geostationary meteorological data. J Climatol 7:1-11

Oke TR (1987) Boundary layer climates. Methuen, London Running SW (1991) Computer simulations of regional evapotranspiration by integrating landscape biophysical attributes with satellite data. In: Schmugge TJ, Andre JC (eds) Land surface evaporation: measurements and parameterization. Springer-Verlag, New York, p 359-369

Schmidt F (1977) Variable fine mesh in spectral global model. Beitr Phys Atmos 50:211-217

Yin JH (2005) A consistent poleward shift of the storm tracks in simulations of 21st century climate. Geophys Res Lett 32, L18701, doi:10.1029/2005GL032684

Submitted: February 13, 2006; Accepted: February 6, 2007

Proofs received from author(s): April 25, 2007 